\title{
ERRATUM
}

\section{Excess of glucocorticoid induces myocardial remodeling and alteration of calcium signaling in cardiomyocytes}

\author{
Priyanka De, Sreerupa Ghose Roy, Dipak Kar and Arun Bandyopadhyay
}

The authors and the journal sincerely apologise for an error in Fig. 2 of this article, published in 2011, vol 209, on pages 105-114. The control (CON) section in Fig. $2 \mathrm{~A}$ and

corresponding column $(\mathrm{CON})$ in Fig. 2C were incorrect and should display as appears below and not as published.
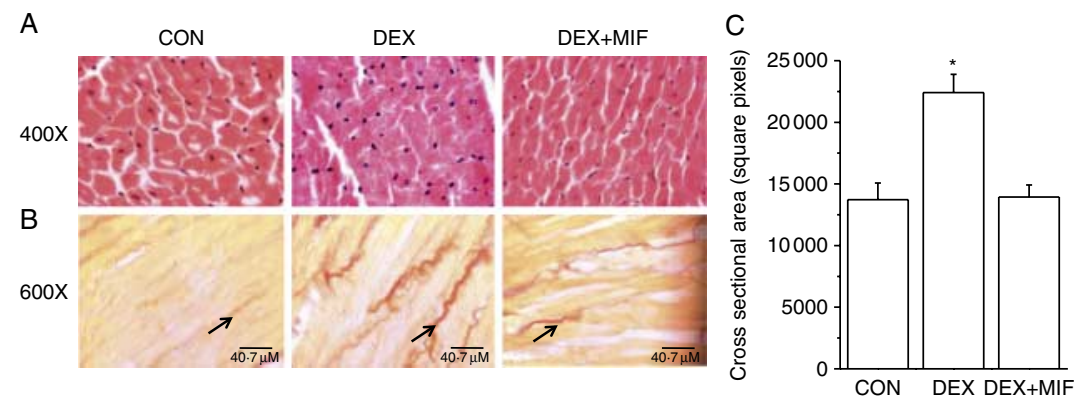

Figure 2 Development of LV fibrosis by dexamethasone. Representative images $(400 \times$ magnification) showing myocyte areas in hematoxylin-eosin-stained cross sections (A) through left ventricles of rats treated with vehicle (CON) or dexamethasone (DEX) or dexamethasone with mifepristone (DEX + MIF) for 15 days. Images $(600 \times$ magnification) of the similar sections (B) stained with Sirius red. Red color stretches (arrow heads) indicate collagen depositions. (C) Myocyte cross-sectional area calculated from the hematoxylinand eosin-stained sections as shown in (A). Each bar represents myocyte cross-sectional areas in mean \pm S.E.M. of square pixels of three images from three individual rats ${ }^{*} P<0 \cdot 01$ versus control, $n=3$ ). Full colour version of this figure available via http://dx.doi.org/10. 1530/JOE-10-0431. 